\title{
Student Internships: A Rich Source of Data for Assessment of Program Outcomes
}

\author{
Susan M. Blanchard, Peter L. Mente, and Lesley H. Hubbard \\ Joint Department of Biomedical Engineering at UNC Chapel Hill and NC State
}

\section{Background}

Students in the Biomedical Engineering (BME) program at NC State University have sought out summer internships, particularly the Research Experiences for Undergraduates that are sponsored by the National Science Foundation, since the program began in the mid 1990s. In addition, NC State University is fortunate to have been one of the many institutions that have benefited from The Whitaker Foundation's industrial internship program in biomedical engineering. This combination of internship opportunities for students offers a rich source of data for assessment of six of the BME program's outcomes: 1.a, 1.e, 2.a, 2.b, 2.d, and 3.c.

The relevant objectives (numbers) and associated outcomes (letters) that can be assessed with data from student internships are given below. The numbers and letters in parentheses refer to ABET outcomes $3 \mathrm{a}-3 \mathrm{k}$.

1. To educate students to be successful in Biomedical Engineering by emphasizing engineering and biology as related to basic medical sciences and human health. After completing the B. S. in Biomedical Engineering, graduates will be able to:

a. Draw on knowledge of mathematics, science, and engineering to critically evaluate, analyze, and solve problems at the interface of engineering and biology by using appropriate tools. (3a, 3b, 3e)

e. Design and conduct experiments to test hypotheses and to make measurements on and interpret data from living systems. (3b, 3e)

2. To produce Biomedical Engineers able to communicate effectively with diverse audiences and prepared to work in multidisciplinary teams.

After completing the B. S. in Biomedical Engineering, graduates will be able to:

a. Deliver effective oral presentations to multiple audiences, including health care and engineering professionals. (3g)

b. Prepare effective written materials. $(3 \mathrm{~g})$

d. Work effectively in multidisciplinary teams to complete projects. (3d)

3. To develop in students professional, ethical, and societal responsibility in Biomedical Engineering practices.

After completing the B. S. in Biomedical Engineering, graduates will be able to: c. Demonstrate professional behavior. (3f) 
Supervisors of students completing industrial internships in summer $2002(\mathrm{~N}=3)$ and $2003(\mathrm{~N}=3)$ and students completing research internships $(\mathrm{N}=9)$ in summer 2003 were asked to complete a survey about how well our students were prepared or performed in 16 different areas. Questions in the survey mapped directly to student learning outcomes for the BME program and to ABET outcomes $3 \mathrm{a}, 3 \mathrm{~b}, 3 \mathrm{~d}, 3 \mathrm{e}, 3 \mathrm{f}$, and $3 \mathrm{~g}$. The available scale was: excellent, very good, average, below average, poor, or not observed. The performance goal was that all of the rated students would perform at the average level or above in all categories.

\section{Results}

The results from the 15 evaluations for the summers of 2002 and 2003 are shown in Table 1. Based on the performance goal, BME summer interns demonstrated competency in outcomes 1.e (ability to design and conduct experiments and interpret data), 2.a (effective oral communication), and 2.d (working effectively on teams). One summer research student performed below the performance criteria for outcomes 1.a (ability to use math, science, and engineering to solve problems) and 3.c (professional behavior) and another summer research student performed below average for outcome $1 . b$ (effective written communication). None of the students in industrial internships was rated below average in any category and most ratings for industrial interns $(92.3 \%)$ were very good or excellent.

Table 1: Supervisor Evaluations of BME Summer Interns

\begin{tabular}{|c|c|c|c|c|c|c|c|}
\hline & \multirow[b]{2}{*}{ BME outcome } & \multicolumn{6}{|c|}{ Rating } \\
\hline & & Excellent & Very Good & Average & $\begin{array}{c}\text { Below } \\
\text { Average }\end{array}$ & Poor & $\begin{array}{c}\text { Not } \\
\text { Applicable }\end{array}$ \\
\hline Expertise in mathematics & $1 . a$ & 0 & 8 & 3 & 0 & 0 & 4 \\
\hline Expertise in science & 1.a & 3 & 9 & 3 & 0 & 0 & 0 \\
\hline Problem-solving skills & $1 . a$ & 7 & 6 & 0 & 1 & 0 & 1 \\
\hline \multirow[t]{3}{*}{ Uses techniques/skills necessary for engineering practice } & 1.a & 3 & 7 & 3 & 0 & 0 & 2 \\
\hline & Sum & 13 & 30 & 9 & 1 & 0 & 7 \\
\hline & Percent total & 21.7 & 50.0 & 15.0 & 1.7 & 0.0 & 11.7 \\
\hline Expertise in designing and conducting experiments & $1 . \mathrm{e}$ & 5 & 7 & 1 & 0 & 0 & 2 \\
\hline \multirow[t]{3}{*}{ Expertise in analyzing and interpreting data } & 1.e & 2 & 9 & 4 & 0 & 0 & 0 \\
\hline & Sum & 7 & 16 & 5 & 0 & 0 & 2 \\
\hline & Percent total & 23.3 & 53.3 & 16.7 & 0.0 & 0.0 & 6.7 \\
\hline \multirow[t]{2}{*}{ Oral expression } & $2 . a$ & 6 & 7 & 2 & 0 & 0 & 0 \\
\hline & Percent total & 40.0 & 46.7 & 13.3 & 0.0 & 0.0 & 0.0 \\
\hline \multirow[t]{2}{*}{ Written expression } & $2 . b$ & 5 & 7 & 1 & 1 & 0 & 1 \\
\hline & Percent total & 33.3 & 46.7 & 6.7 & 6.7 & 0.0 & 6.7 \\
\hline Relationships with others & $2 . d$ & 11 & 4 & 0 & 0 & 0 & 0 \\
\hline \multirow[t]{3}{*}{ Uses leadership skills } & $2 . d$ & 1 & 6 & 3 & 0 & 0 & 5 \\
\hline & Sum & 12 & 10 & 3 & 0 & 0 & 5 \\
\hline & Percent total & 40.0 & 33.3 & 10.0 & 0.0 & 0.0 & 16.7 \\
\hline Quality of work & $3 . c$ & 10 & 4 & 1 & 0 & 0 & 0 \\
\hline Quantity of work & 3.c & 5 & 9 & 0 & 1 & 0 & 0 \\
\hline Completion of assignments & 3.c & 9 & 4 & 2 & 0 & 0 & 0 \\
\hline Acceptance of responsibilities & 3.c & 11 & 3 & 1 & 0 & 0 & 0 \\
\hline Takes direction & 3.c & 9 & 5 & 1 & 0 & 0 & 0 \\
\hline \multirow[t]{3}{*}{ Work attitudes (e.g. initiative, enthusiasm) } & 3.c & 12 & 2 & 1 & 0 & 0 & 0 \\
\hline & Sum & 56 & 27 & 6 & 1 & 0 & 0 \\
\hline & Percent total & 62.2 & 30.0 & 6.7 & 1.1 & 0.0 & 0.0 \\
\hline
\end{tabular}


Although the number of participating students for any given summer may be small, the combined results over time can provide important information for guiding programmatic decision making.

SUSAN M. BLANCHARD, Ph.D.

Dr. Blanchard received the A.B. in Biology from Oberlin College in 1968 and the M.S. and Ph.D. degrees in Biomedical Engineering from Duke University in 1980 and 1982, respectively. She is currently a

Professor at North Carolina State University in the Joint Department of Biomedical Engineering, a Senior Member of the Biomedical Engineering Society, and a Fellow of AIMBE and the IEEE.

PETER L. MENTE, Ph.D.

Peter L. Mente received a B.A in Biology from the University of Chicago in 1983 and his M.S. and Ph.D. degrees in Biomedical Engineering from Northwestern University in 1987 and 1995 respectively. He is

currently an Assistant Professor at North Carolina State University in the Joint Department of Biomedical Engineering at UNC Chapel Hill and NC State.

\section{LESLEY H. HUBBARD}

Lesley H. Hubbard received a B.S. in Elementary Education from Appalachian State University in 1993. She is currently a Student Services Assistant at North Carolina State University in the Joint Department of Biomedical Engineering at UNC Chapel Hill and NC State. 